Froes,T.R.'; Gonzalez, J.R.M. ${ }^{2}$; Kanayama, L.M. ${ }^{3}$; Costa, R.J. ${ }^{3}$; Iwasaki, M. ${ }^{4}$

\section{1 - Ultra-sonografia intervencionista: drenagem percutânea de cistos e abscessos prostáticos em cães. Estudo de casos}

1-Doutoranda do Departamento de Cirurgia da Faculdade de Medicina Veterinária e Zootecnia da Universidade de São Paulo, São Paulo-SP

2- Professora Doutora do Departamento de Ciências Veterinárias da Universidade Estadual de Londrina, Londrina-PR

3- Médicos Veterinários do Hospital Veterinário da Faculdade de Medicina Veterinária e Zootecnia da Universidade de São Paulo, São Paulo-SP

4- Professor Titular do Departamento de Cirurgia da Faculdade de Medicina Veterinária e Zootecnia da Universidade de São Paulo, São Paulo-SP

A ultra-sonografia intervencionista é um método diagnóstico ou terapêutico pouco invasivo, altamente eficiente e já consolidado na medicina humana, sendo as complicaçooes raramente observadas. A drenagem de cistos e abscessos prostáticos foi pouco estudada na medicina veterinária. $\mathrm{O}$ objetivo deste trabalho foi avaliarmos a eficácia da drenagem percutânea eco-dirigida nas lesões císticas ou cavitárias da próstata de cães. Foram estudados 15 cães com cistos ou lesões cavitárias prostáticas e/ou paraprostáticas, identificadas ao exame ultra-sonográfico, no periodo de setembro de 2000 a junho de 2002. Os critérios ultrasonográficos de inclusão foram: presença de lesões císticas ou cavitárias maiores que $1,5 \mathrm{~cm}$ encontradas em pacientes com sinais clínicos de afecção prostática. Todos os procedimentos foram realizados com consentimento informado do proprietário. O procedimento intervencionista foi realizado com transdutores de 5,0 e 7,5 $\mathrm{MHz}$, sob anestesia geral. Nos pacientes que não estavam sob antibioticoterapia, a mesma foi realizada por via intravenosa imediatamente antes do procedimento, sendo a escolha da droga e posologia determinadas segundo os critérios do médico veterinário responsável pelo caso. Selecionamos agulhas hipodérmicas de diferentes tamanhos ou mandril metálico de cateteres endovenosos, de acordo com a profundidade da lesão. Após a anti-sepsia local, dirigimos a agullha / cateter até a lesão, acompanhando a introdução da mesma na imagem ultra-sonográfica. Em todos os animais a próstata estava subjetivamente aumentada e observamos pelo menos 2 lesões císticas ou cavitárias maiores que $1,5 \mathrm{~cm}$ de diâmetro, preenchidas por conteúdo de variada ecogenicidade. A quantidade de líquido aspirado variou de $10 \mathrm{ml}$ a $130 \mathrm{ml}$ (média $63 \mathrm{ml}$ ) nas lesões intraprostáticas e nos cistos paraprostáticos a quantidade de líquido removido foi de $290-600 \mathrm{ml}$ (média $590 \mathrm{ml}$ ). Em 10 animais o líquido aspirado tinha características e coloraçào de pus, 1 sero-sanguinolento, 2 pio-sangüinolenta e 2 sanguinolenta. Os microorganismos identificados nos conteúdos aspirados foram: $3(20 \%)$ Escherichia Coli, 1(6,7\%) Staplylococcus Aureus, 1 (6,7\%) Klebsiella, 2 (13,3\%) Streptococcus B Hemolitico e em $08(53,3 \%)$ não foram identificados microorganismos. Em 13 animais obtivemos sucesso terapêutico. Um animal veio a óbito decorrente de sepse devido a suspensão precoce e indevida da antibioticoterapia por parte do proprietário. Em apenas um animal não houve a resolução clínica do processo. Não foram observadas complicações durante as drenagens em nenhum dos animais. Logo após a primeira drenagem todos os animais apresentaram melhora clínica evidente, e ao exame ultrasonográfico controle ( 1 semana) as lesões estavam pelo menos $50 \%$ menores quando comparadas ao exame anterior a drenagem $\mathrm{Na}$ maioria dos casos foram necessárias duas punções para a remissão completa das lesòes. A ultra-sonografia intervencionista é uma técnica minimamente invasiva e segura para o tratamento das lesões císticas ou cavitárias da próstata de cães. 